\title{
Disability-Adjusted Life Years for the COVID-19 Pandemic in the Mexican Population
}

\begin{abstract}
Guillermo Salinas-Escudero ${ }^{1}$, Filiberto Toledano-Toledano ${ }^{2}$, Carmen García-Peña ${ }^{3}$, Lorena Parra-Rodríguez ${ }^{3}$, Víctor Granados-García ${ }^{4}$ and María Fernanda Carrillo-Vega ${ }^{3 *}$

${ }^{1}$ Hospital Infantil de México Federico Gómez, Centro de Estudios Económicos y Sociales en Salud, Ciudad de México, Mexico, ${ }^{2}$ Hospital Infantil de México Federico Gómez, Unidad de Investigación de Medicina Basada en Evidencia, Ciudad de México, Mexico, ${ }^{3}$ Instituto Nacional de Geriatría, Dirección de Investigación, Ciudad de México, Mexico, ${ }^{4}$ Instituto Mexicano del Seguro Social, Centro Médico Nacional Siglo XXI, Unidad de Investigación en Epidemiología y Servicios de Salud, Área de Envejecimiento, Ciudad de México, Mexico
\end{abstract}

Mexico is one of the countries most affected by the COVID-19 disease. Although there is vast information on the disease, there still are unknown data on the societal and economic cost of the pandemic. To estimate this impact, the disability-adjusted life years (DALYs) can be a useful tool.

OPEN ACCESS

Edited by:

Shunmay Yeung,

University of London, United Kingdom

Reviewed by:

Zhongqing $X u$,

Shanghai Jiao Tong University School

of Medicine, China

Juliana Maria Trindade Bezerra, State University of Maranhão, Brazil

*Correspondence: María Fernanda Carrillo-Vega marifercave@yahoo.com.mx

Specialty section: This article was submitted to Infectious Diseases - Surveillance,

Prevention and Treatment,

a section of the journal

Frontiers in Public Health

Received: 27 March 2021

Accepted: 02 July 2021

Published: 17 August 2021

Citation:

Salinas-Escudero G, Toledano-Toledano F, García-Peña C,

Parra-Rodríguez L,

Granados-García V and

Carrillo-Vega MF (2021)

Disability-Adjusted Life Years for the

COVID-19 Pandemic in the Mexican

Population.

Front. Public Health 9:686700.

doi: 10.3389/fpubh.2021.686700
Objective: To assess the DALYs due to COVID-19 in Mexico.

Methods: We used the data released by the Mexican Ministry of Health to estimate the DALYs by the sum of the years of life lived with disability (YLDs) and the years of life lost (YLLS).

Results: A total of 1,152,885 confirmed cases and 324,570 suspected cases of COVID-19 have been registered. Half of the cases were men, with a median age of 43.4 \pm 16.9 years. About $8.3 \%$ died. A total of 39,202 YLDs were attributable to COVID-19. The total YLLs caused by COVID-19 were 2,126,222. A total of 2,165,424.5 DALYs for COVID-19 were estimated. The total DALYs were the highest in people between 50 and 59 years. The DALYs for each COVID-19 case were the highest in individuals between 60 and 79 years.

Conclusion: The DALYs generated by the COVID-19 represent a more significant disease burden than that reported for other causes, such as the $2009 \mathrm{H} 1 \mathrm{~N} 1$ influenza pandemic. Although it impacts all age groups in terms of disability, the most affected group are people over 50 years of age, whose risk of death is higher.

Keywords: COVID-19, SARS-CoV-2, global burden of disease, México, DALYs, YLLs, YLDs

\section{INTRODUCTION}

The novel coronavirus is spreading worldwide, causing diverse adverse consequences (1-7). Numbers continuously change, and currently, most countries face second and third waves, with a larger number of cases burdening of the health systems (8-13). Over 85 million individuals have been infected, with $\sim 2$ million deaths (14). Among the WHO regions, the American continent ranks first in the number of infections ( $43 \%$ of all accumulated cases) and deaths ( $47 \%$ of all deaths) (14). The United States and Brazil are in leading in these numbers with increasing rates of infection and mortality. Other countries in the continent have a high toll, such as Colombia and Mexico (14). 
There is a thorough epidemiological characterization of the disease. In particular, sex (men) and old age have been consistently reported as risk factors for COVID-19 $(15,16)$. The Latin American region has shown to be especially vulnerable to the morbid consequences of this pandemic due to the high prevalence of chronic diseases (e.g., diabetes and hypertension) and obesity that have been associated with adverse outcomes of younger individuals (17-21). Moreover, inequality stakes. For example, there is evidence that, in Mexico, living in municipalities with higher marginalization and being indigenous is associated with higher transmission rates and an ominous course of the disease for those who develop it $(22,23)$.

Despite efforts to better understand the disease behavior, there are still unknown societal and economic costs. Disabilityadjusted life years (DALYs) are a metric quantifying and combining premature death and disability resulting from the disease to estimate its impact on the population (24). DALYs represent a tool to determine both the burden of disease and the intervention effects such as mass vaccination. Estimates of DALYs from Italy, Korea, and Japan have been released. However, those for Latin America, and specifically for Mexico (24-26), are missing. Thus, the present study aimed to assess the DALYs due to COVID-19 in Mexico.

\section{METHODS}

\section{Study Area}

Mexico has a population of 127.79 million people, out of which $51 \%$ are women. Of the total, $34.5 \%$ are people below 20 years, $54.2 \%$ are people between 20 and 59 years, and $11.3 \%$ are people aged 60 years and over (27). About $74 \%$ of the total is affiliated with one or more public health services (28). The life expectancy at birth in 2020 was 78.11 years for women and 72.37 years for men. The per capita gross product is US\$19,162 and the health expenditure is US\$1,154 (29).

\section{Methods}

We used the data released by the Mexican Ministry of Health (30), whose characteristics have been previously described $(17,18,30)$. In brief, the database includes information on negative, confirmed, and suspected COVID-19 cases. Data on demographic characteristics (sex, age, nationality, residence place, and migratory status) and risk factors for severe COVID19 (smoking and pregnancy) were registered. Information on morbidity, type of medical attention received (outpatient management or hospitalization), the medical unit where attended (public or private), dates when individuals developed symptoms, dates when they were admitted to the hospital and died is available. No information on evolution can be explored using this dataset.

Although the first case in Mexico was reported on February 27,2020 , we assumed that symptoms began 5 days before the individual search for medical care, so all the cases that reported the start of symptoms on February 22, 2020 were included. The inclusion date for counting cases in the present analysis was December 4, 2020. All COVID-19 cases confirmed with real-time reverse transcription PCR (RT-PCR) assay, independently of the signs and symptoms (31), clinical association, or experts committee were included (32-34).

Suspected cases represent a substantial proportion of the dataset. These cases are defined as the following: a person with acute onset of fever and cough or acute onset of any three or more of the following signs or symptoms: fever, cough, general weakness/fatigue, headache, myalgia, sore throat, coryza, dyspnea, anorexia/nausea/vomiting, diarrhea, and altered mental status; a person residing or working in a setting with a high risk of transmission of the virus, for example, closed residential settings and humanitarian settings, such as camp and camplike settings for displaced persons, any time within the 14 days before symptom onset; a person residing in or travel to an area with community transmission anytime within the 14 days before symptom onset; a person working in a health setting, including within health facilities and within households, anytime within the 14 days before symptom onset; a patient with severe acute respiratory illness (SARI: acute respiratory infection with history of fever or measured fever of $\geq 38^{\circ} \mathrm{C}$; and cough; with onset within the last 10 days; and who requires hospitalization); or an asymptomatic person not meeting epidemiologic criteria with a positive SARS-CoV-2 antigen-detecting rapid diagnostic test (Ag-RDT) (31). Based on the reasoning that suspected cases could underestimate the DALYs, we decided to include those reported as suspected in the period between September 1 and December 31, 2020. We considered that these cases were potentially positive COVID-19 as the result of the PCR test was still pending. The total suspected cases were adjusted by the positivity rate for COVID-19 corresponding to the 1st week of December 2020 (47.2\%) (35). The cases reported as negative to the RT-PCR assay or those with insufficient information for its classification were excluded.

The DALYs were estimated by summing the years of life lived with disability (YLDs) and the years of life lost (YLLs), (36) as follows:

\section{DALY $=$ YLDs + YLLs}

For this purpose, YLDs were estimated considering the status of the individual. For death, the period from the onset of symptoms to death date was counted as the time of disability, regardless of health care received (ambulatory or inpatient). The dataset does not include information on the disease remission date or discharge date for those alive. However, the average time from the onset of symptoms to seeking medical attention is reported. Based on this information, the time between seeking care and discharge was estimated by a linear extrapolation, assuming that the disease had the same time course in dead and surviving patients. Finally, a ponderation by type of health care received (outpatient or hospitalization) was conducted. This estimation was done as follows:

YLDs $($ death $)=($ Death date-seeking medical attention date in deaths) + (seeking medical attention date in deathsSymptoms date in deaths)

YLDs (no deaths) $=$ (Discharge date-seeking medical attention date) + (seeking medical attention date in no deaths-Symptoms date in no deaths) 
where Discharge date $=[($ Death date-seeking medical attention date in deaths)/(seeking medical attention date in deaths-Symptoms date in deaths)] * [seeking medical attention date in no deaths-Symptoms date in no deaths]

Although long-term effects of COVID-19 have been described $(37,38)$, the dataset does not include data on post-COVID-19 signs and symptoms. Therefore, disability time was counted as the period of limitation and not that for sequels. A disability weight of one during the disease period was assumed. No reference reports this weight, so we took into account some elements to support this decision. First, for patients who needed to be hospitalized, who needed mechanical ventilation machine, and who were entered to ICU, we considered that the weight is very close to the unit due to the severity of the disease. For the outpatient cases, regardless of whether they were suspected or confirmed cases, the majority have to be in quarantine or total isolation, and as a result, the period of disability corresponds to those days in quarantine. Additionally, it was considered that those individuals who survived recovered their full health when the quarantine period ends.

The YLLs were obtained by subtracting the age of the person at death to life expectancy reported in the Mexican life tables, adjusted for sex and age. For this purpose, the life expectancy of the Mexican population adjusted by sex for 2019 was used (39). The final estimate of YLLs includes a $1 / 2$-year adjustment to avoid an underestimation or overestimation in the parameter:

$$
\text { YLLs }=\text { Life expectancy }-(\text { Age of death }-0.5)
$$

Two scenarios were estimated for the YLLs. The first with raw values and the second using a 5\% discount. For people over 106 years, the value discounted for those of 105 years was used.

Additionally, the per capita DALYs were stratified into age classes. To this end, the total DALYs by age group were divided by the people with COVID-19 in each group.
Finally, the rates for DALYs, YLLs, and YLDs per 100,000 inhabitants were calculated using the population officially reported for the country (40).

\section{Statistical Analysis}

Descriptive analysis was performed. Continuous variables are presented as means and SDs, and categorical variables are expressed as frequencies and percentages. Comparisons between confirmed and suspected cases were estimated through the Mann-Whitney test for continuous variables and $\chi^{2}$ for categorical variables. The dataset was analyzed using the statistical package software STATA 14. Microsoft Excel 365 was used for the preparation of charts and graphs.

\section{Ethics}

The submission of a formal protocol to the research and ethics committees is not required as the dataset is public and does not have personal data that allows the identification of individuals. However, the data analysis was registered with the National Institute of Geriatrics (registration number DI-PI-002/202).

\section{RESULTS}

Between February 22 and December 4, 2020, 1,152,885 confirmed and 324,570 suspected cases of COVID-19 have been registered in Mexico. Half of the cases were men, with a median age of $43.4 \pm 16.9$ years. About $20 \%$ of the sample was hospitalized, $15 \%$ was intubated, $8.5 \%$ was entered into the ICU, and $8.3 \%$ died. Although comparison was not the'primary objective of the present analysis, a higher proportion of confirmed cases was hospitalized, intubated, and entered the ICU compared with the suspected cases $(p<0.01)$. In the group of confirmed cases, there was higher mortality (9.4 vs. $4.2 \%, p<0.01)$. The period between the symptoms starting from admission and

TABLE 1 | General characteristics ${ }^{\mathrm{a}}$.

\begin{tabular}{|c|c|c|c|c|}
\hline & $\begin{array}{c}\text { Total } \\
n=1,477,455\end{array}$ & $\begin{array}{c}\text { Confirmed cases } \\
n=1,152,885\end{array}$ & $\begin{array}{l}\text { Suspected cases } \\
n=324,570\end{array}$ & $p$ \\
\hline \multirow[t]{2}{*}{ Sex (men) } & $745,053(50.4)$ & $584,976(50.7)$ & $160,077(49.3)$ & \\
\hline & & & & $<0.001^{\star \star}$ \\
\hline \multirow[t]{2}{*}{ Age (years) } & $43.4 \pm 16.9$ & $44.2 \pm 16.8$ & $40.7 \pm 16.8$ & \\
\hline & & & & $<0.001^{*}$ \\
\hline \multirow[t]{2}{*}{$\mathrm{ICU}$} & 24,267 (8.5) & 21,106 (8.6) & $3,161(7.7)$ & \\
\hline & & & & $<0.001^{\star}$ \\
\hline \multirow[t]{2}{*}{ Dead } & $121,981(8.26)$ & $108,215(9.4)$ & 13,766 (4.2) & \\
\hline & & & & $<0.001^{\text {** }}$ \\
\hline Days Syntom-Admission & $4.199 \pm 3.4$ & $4.2 \pm 3.3$ & $4.1 \pm 3.8$ & $<0.001^{\text {** }}$ \\
\hline
\end{tabular}

${ }^{a}$ Continuous variables are presented as Means \pm Standard Deviation; categorical variables are presented as Frequencies (percentages).

${ }^{*} X^{2}$ and Exact Fisher's test.

${ }^{* *}$ Mann-Whitney test. 
TABLE 2 | Fatality rate for COVID-19 by age group.

\begin{tabular}{|c|c|c|c|c|c|}
\hline Age group & Cases & $\%$ & Deads & $\%$ & Fatality rate \\
\hline \multicolumn{6}{|c|}{ Confirmed cases } \\
\hline $0-9$ & 12,974 & 1.13 & 244 & 0.23 & 1.88 \\
\hline $20-29 y$ & 190,823 & 16.55 & 1,212 & 1.12 & 0.64 \\
\hline $30-39 y$ & 253,037 & 21.95 & 4,325 & 4.00 & 1.71 \\
\hline $60-69$ y & 123,544 & 10.72 & 30,091 & 27.81 & 24.36 \\
\hline $70-79 y$ & 64,614 & 5.60 & 23,835 & 22.03 & 36.89 \\
\hline $80-89$ y & 24,835 & 2.15 & 11,072 & 10.23 & 44.58 \\
\hline$\geq 90 y$ & 4,032 & 0.35 & 1,708 & 1.58 & 42.36 \\
\hline Total & $1,152,885$ & & 108,215 & & \\
\hline $20-29 y$ & 70,300 & 21.66 & 195 & 1.42 & 0.28 \\
\hline $30-39 y$ & 75,651 & 23.31 & 610 & 4.43 & 0.81 \\
\hline $40-49 y$ & 64,783 & 19.96 & 1,657 & 12.04 & 2.56 \\
\hline $50-59 y$ & 47,567 & 14.66 & 2,939 & 21.35 & 6.18 \\
\hline $60-69$ y & 25,554 & 7.87 & 3,767 & 27.36 & 14.74 \\
\hline $70-79 y$ & 13,211 & 4.07 & 2,842 & 20.65 & 21.51 \\
\hline $80-89$ y & 5,232 & 1.61 & 1,430 & 10.39 & 27.33 \\
\hline$\geq 90 y$ & 1,048 & 0.32 & 268 & 1.95 & 25.57 \\
\hline Total & 324,570 & & & & \\
\hline \multicolumn{6}{|c|}{ Adjusted suspected cases (47.2\%) } \\
\hline $0-9$ & 3,467 & 2.17 & 7 & 0.22 & 0.20 \\
\hline 80-89 & 2,500 & 1.57 & 404 & 12.87 & 16.16 \\
\hline$\geq 90 y$ & 487 & 0.3 & 72 & 2.29 & 14.78 \\
\hline Total & 159,718 & & & & \\
\hline
\end{tabular}

the occurrence of death was longer in the confirmed cases $(p<0.01)$ (Table 1).

It can be seen in Table 2 that the fatality rate increased with age, doubling in the 50-59 age group compared with the preceding group, and is close to $45 \%$ in the $80-89$, decreasing by about three percentage points in the oldest age group (older than 90 years). Among the suspected cases, the fatality rate is lower, especially in the adjusted cases, in which the highest rate is $16 \%$ in the oldest age group.

A total of 39,202 YLDs attributable to COVID-19, primarily determined by the confirmed cases, were estimated. The burden of YLDs was highest in those people at the age of most significant productivity (30-59 years). The total YLLs caused by COVID19 was $2,126,222$; the confirmed cases significantly contribute to this figure. The highest number of YLLs was observed between 30 and 79 years (Table $\mathbf{3 A}$ ). It can be noted that the discount mainly affects the YLLs, that is, the discount rate minimizes the adverse health outcomes of the YLLs that are spread over time. On the other hand, the YLDs are assumed to occur during the period of illness ( $<1$ year). It can be seen that about 1 million YLLs decreased when applying the discount rate (Table $3 \mathrm{~B}$ ).

A total of 2,165,424.5 DALYs for COVID-19 was estimated. When applying the discount rate, 1,384,227.4 DALYs resulted. The total DALYs were highest in the 50-59 years age group but were higher in the 60-69 years group when applying the discount rate. Almost two DALYs can be attributable to each COVID-19 case. It can be seen that each COVID-19 case 
TABLE 3 | Years of life lived with disability (YLDs) and the years of life lost (YLLs) by age group.

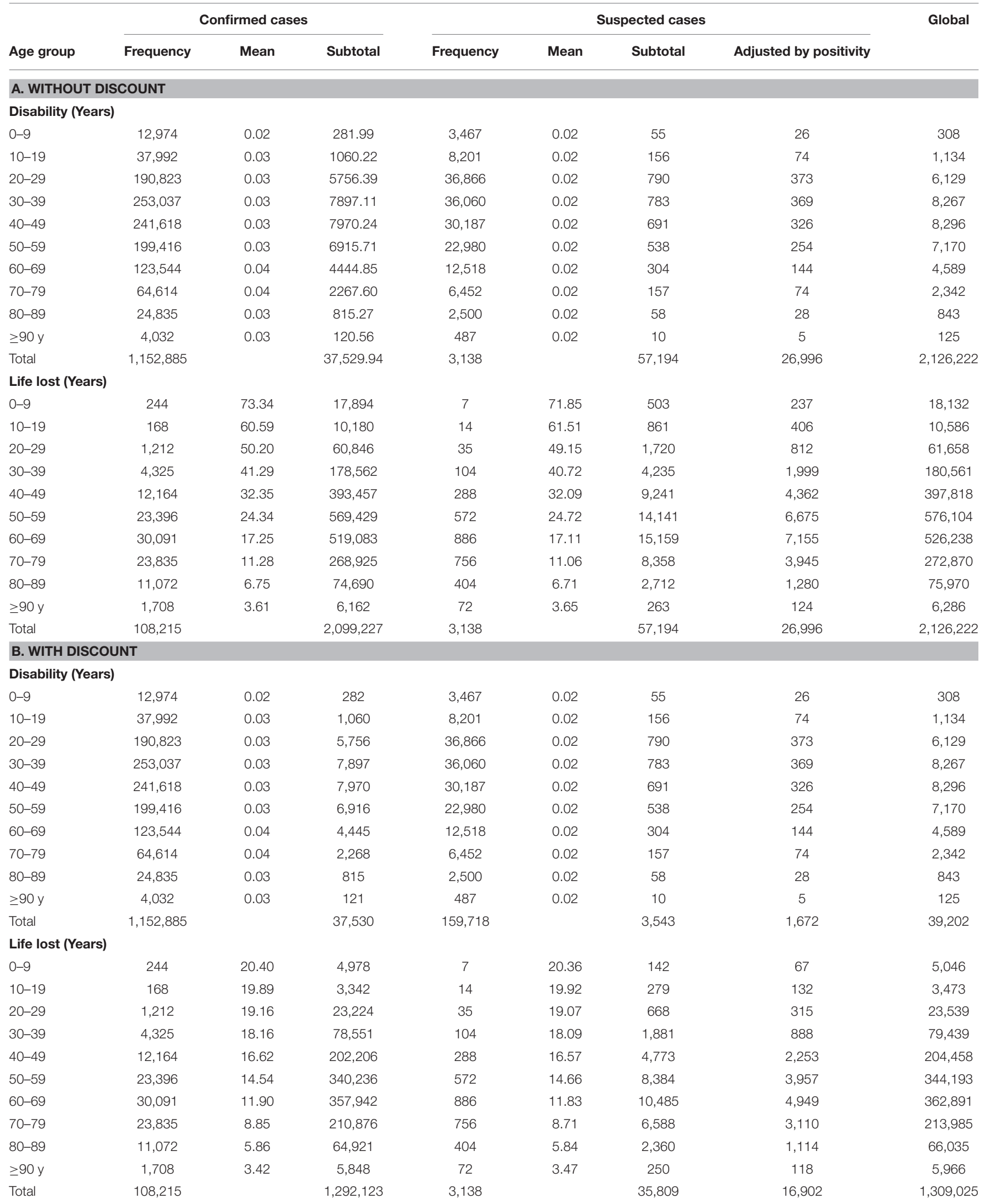


TABLE 4 | Total disability-adjusted life years (DALYs) by COVID-19 case.

\begin{tabular}{|c|c|c|c|c|c|c|c|c|c|}
\hline Age group & $\begin{array}{l}\text { COVID cases } \\
\text { and suspect } \\
\text { cases adjusted }\end{array}$ & $\begin{array}{c}\text { Premature } \\
\text { dead }\end{array}$ & $\begin{array}{l}\text { Premature dead } \\
\text { discounted }\end{array}$ & Disability & $\begin{array}{l}\text { Disability } \\
\text { discounted }\end{array}$ & Total & $\begin{array}{c}\text { Total } \\
\text { discounted }\end{array}$ & $\begin{array}{c}\text { Life of } \\
\text { years lost } \\
\text { by case }\end{array}$ & $\begin{array}{c}\text { Life of years } \\
\text { lost by } \\
\text { confirmed } \\
\text { case discounted }\end{array}$ \\
\hline $0-9$ & 12,977 & $18,131.6$ & $5,045.7$ & 307.8 & 307.8 & $18,439.4$ & $5,353.5$ & 1.42 & 0.41 \\
\hline $10-19$ & 37,999 & $10,586.0$ & 3,473.4 & $1,134.0$ & $1,134.0$ & $11,720.0$ & $4,607.4$ & 0.31 & 0.12 \\
\hline 20-29 & 190,840 & $61,657.9$ & $23,538.9$ & $6,129.1$ & $6,129.1$ & $67,787.0$ & $29,668.0$ & 0.36 & 0.16 \\
\hline $40-49$ & 241,754 & $397,818.2$ & $204,458.4$ & $8,296.4$ & $8,296.4$ & $406,114.6$ & $212,754.8$ & 1.68 & 0.88 \\
\hline $50-59$ & 199,686 & $576,104.0$ & $344,192.9$ & $7,169.5$ & $7,169.5$ & $583,273.5$ & $351,362.5$ & 2.92 & 1.76 \\
\hline $60-69$ & 123,962 & $526,238.3$ & $362,890.5$ & 4,588.6 & $4,588.6$ & $530,826.8$ & $367,479.1$ & 4.28 & 2.96 \\
\hline 70-79 & 64,971 & $272,869.7$ & $213,985.5$ & $2,341.9$ & $2,341.9$ & $275,211.6$ & $216,327.4$ & 4.24 & 3.33 \\
\hline 80-89 & 25,026 & $75,970.5$ & $66,035.0$ & 842.9 & 842.9 & $76,813.4$ & $66,877.9$ & 3.07 & 2.67 \\
\hline
\end{tabular}

between 60 and 79 years of age generates the most DALYs (Table 4).

The general rate of YLLs, YLDs, and DALYs per 100,000 inhabitants was $1,663.8,30.7$, and 1,055, respectively. The highest rates of YLLs per 100,000 were observed in the 60-69 and the 70-79 years groups. The highest rate of YLDs per 100,000 was observed in the 50-69 years group. Finally, the highest rate of DALYs per 100,000 was observed in the 70-79 years group (Table 5).

\section{DISCUSSION}

The present study represents the first effort to understand the burden of COVID-19 in Mexico. According to our results, the total DALYs were the highest in people between 50 and 59 years, followed by individuals in the 60-69 years old group. The DALYs for each COVID-19 case were the highest in individuals between 60 and 79 years.

In line with official reports, the COVID-19 was the second cause of death in Mexico from January to August 2020, standing below cardiovascular disease and above diabetes, the two leading causes of death in the previous years (41). This information can sustain our results on mortality (YLLs) as the component that primarily determined the actual pandemic burden in Mexico, contributing $97.1 \%$ to the total DALYs. Similar results on the burden of the COVID-19 in other countries had been previously reported $(24,25)$.

A significant finding is that most YLLs were observed in individuals between 50 and 59. This information is similar to that previously reported about low and mid-income countries, where a significant fraction of the YLLs caused by the COVID19 is from individuals dying at ages 55 or younger (42). During the AH1N1 pandemic of 2009, a similar behavior was observed; the younger population (20-59 years) determined the most YLLs (43). Notably, the'weight of YLLs for individuals between 20 and 59 years in our population was considerably higher $(1,216,140.75$ YLLs) in the COVID-19 pandemic than for the same age group during the 2009 pandemic (467,640 YLLs), even though the follow-up period in the present analysis was shorter.

In the present analysis, YLDs contributed less to total DALYs. This information is in harmony with other reports on the burden of the COVID-19 disease $(24,25)$ but not with reports on the DALYs generated by other communicable diseases $(44,45)$. This disagreement can be explained by the lack of information about the disability caused by the COVID-19. In this respect, it should be considered that some sequelae of the disease could appear long after having suffered it and for a prolonged period; consequently, we need to have more accurate data in this regard. The information generated on the sequelae and disability of COVID-19 will be beneficial as YLDs are considered an indispensable component for decision-making as they allow estimating the long-term effects of the disease.

Establishing information on the extended effects is of significant interest since it would allow setting the implications for both individuals and the health system in the future at a social and economic level. Nevertheless, it must be recognized that the information generated thus far had served as the basis for decision-making regarding COVID-19 vaccination campaigns. For example, it is well-known that the chronological age is not the condition that increases the risk of severe disease and death but the multimorbidity and frailty associated with a person. Thus, prioritizing vaccination in this group (46) could reduce the burden of COVID-19 and the high costs of its care.

It is essential to highlight that, in Mexico, as in other countries, the COVID-19 pandemic has strongly impacted the care of other diseases due to saturation at hospitals, the decrease in available personnel, and the redirection of resources to attend the pandemic emergency. The global production of medicines has been affected by social distancing and quarantines, decreasing medical treatments supply worldwide. Consequently, changes in the trend of the burden of other diseases will be observed in the following months, when complications from neglected diseases, including disability and death, appear more evident. 
TABLE 5 | YLLs, YLDs, and DALYs per 100,000 inhabitants in México.

\begin{tabular}{|c|c|c|c|c|}
\hline Age group & Total population & YLLs per 100,000 & YLDs per 100,000 & DALYs per 100,000 \\
\hline $0-9$ & $21,849,433$ & 83.0 & 1.4 & 24.5 \\
\hline $10-19$ & $22,185,367$ & 47.7 & 5.1 & 20.8 \\
\hline $20-29$ & $21,479,518$ & 287.1 & 28.5 & 138.1 \\
\hline 30-39 & $18,897,970$ & 955.5 & 43.7 & 464.1 \\
\hline $40-49$ & $16,198,907$ & $2,455.8$ & 51.2 & $1,313.4$ \\
\hline $70-79$ & $4,225,668$ & $6,457.4$ & 55.4 & $5,119.4$ \\
\hline 80-89 & $1,685,933$ & $4,506.1$ & 50.0 & $3,966.8$ \\
\hline$\geq 90 y$ & 349,482 & $1,798.5$ & 35.9 & $1,742.9$ \\
\hline Total & $127,792,286$ & $1,663.8$ & 30.7 & $1,055.0$ \\
\hline
\end{tabular}

As a reflective exercise, we consider that the burden of the disease can also measure the effectiveness of public health policies and commitment of society to them. Up to this point in the pandemic, it is possible to say that there have been some contradictions in the official discourse of political and health leaders. The social commitment to adherence of basic norms of social distancing and hygiene and the use of face masks have not been as strong as desired, likely because of the lack of clear messages from policymakers. This lack of adherence has significantly determined the continuity in the virus transmission rate and the incidence of severe cases and mortality. Notwithstanding, as stated by the United Nations, the virus does not discriminate; but its impacts do (47). In this sense, it is necessary to reconsider that, in low and mideconomic counties, the effect of a total restriction in mobility also implies inequalities in access to resources, healthcare, education, social protection, and an exacerbation of discrimination, gender inequality, xenophobia, and domestic violence (48). Therefore, the pandemic response must come from different sectors so that the vaccination campaigns allow the transmission of the virus to cease to decrease the impact of YLDs and YLLs.

There are some limitations to this study. First, since the public health strategy of Mexico has not been applying massive detection tests, a significant percentage of asymptomatic and mild level cases could be under-registered. A slight impact on the YLLs would be expected because of these cases. Another factor to consider would be that COVID-19 deaths may not be correctly recorded, underestimating the actual lethality associated with COVID-19 and, therefore, the estimated YLLs.

Second, as mentioned above, information on the long-term effects of COVID-19 is not available in the present dataset, but the sequelae can lead to considerable underestimation of the total disease burden was not taken into consideration. That is why we decided to approach the phenomenon of disability through a coefficient of 1 . Nevertheless, we suggest carefully analyzing the results on YLDs and consider that probabilities can change depending on other factors. For example, a coefficient $<1$ can be observed in those positive cases that, despite being in quarantine, carry out activities close to normal at home. Another consideration would be mild cases of illness that did not contact health providers and continued their normal activities outside the home, and asymptomatic cases that would not have sequelae. Despite these limitations, our results advanced in the phenomenon of disability secondary to COVID-19 and could give birth to new estimation strategies.

When interpreting our results, it should be considered that, by equating the duration of the disease in the cases that survived and those who died, we can overestimate the number of survivors. This assumption, however, corrects in some way the lack of data on the discharge of cases that did not die and was the approach that we consider the most appropriate to solve this limitation.

Finally, it is likely that when reading this study, the inclusion of suspected cases in the analysis will be questioned. In this regard, we suggest considering that several limitations in delivering laboratory test results are observed in Mexico. This fact represents a source of bias that tends to underestimate positive cases. That is why we tried to solve this limitation by applying the positivity rate to the suspected cases.

\section{CONCLUSIONS}

The DALYs generated by the COVID-19 represent a more significant disease burden than that reported for other causes, such as the $2009 \mathrm{H} 1 \mathrm{~N} 1$ influenza pandemic. Although it impacts all age groups in terms of disability, the most affected group are people over 50 years of age, whose risk of death is higher. The data shown in the present study, together with other previously published, should be taken into account to plan disease prevention and control strategies, including vaccination campaigns and the necessary social distancing and hygiene measures to prevent the spread of the virus and its new strains.

\section{DATA AVAILABILITY STATEMENT}

Publicly available datasets were analyzed in this study. This data can be found here: https://datos.gob.mx/busca/dataset/ informacion-referente-a-casos-covid-19-en-mexico.

\section{AUTHOR CONTRIBUTIONS}

GS-E and MC-V: conceptualization. GS-E, MC-V, and FT-T: data curation and supervision. GS-E and LP-R: formal analysis. MC-V, GS-E, CG-P, and VG-G: investigation. MC-V, GS-E, 
CG-P, VG-G, and FT-T: methodology. GS-E, MC-V, and CG-P: writing-original draft. GS-E, MC-V, CG-P, VG-G, LP-R, and FT-T: writing-review \& editing. All authors contributed to the article and approved the submitted version.

\section{FUNDING}

The publication of this paper was supported by a grant from the Secretaría de Educación, Ciencia, Tecnología e Innovación de la

\section{REFERENCES}

1. Guo Y, Sims OT, Qin W, Yang F. Factors associated with symptoms of depression and psychological distress during the COVID-19 pandemic. Behav Sci (Basel). (2021) 11:13. doi: 10.3390/bs11020013

2. Kotlar B, Gerson E, Petrillo S, Langer, A, Tiemeier H. The impact of the COVID-19 pandemic on maternal and perinatal health: a scoping review. Reprod Health. (2021) 18:10. doi: 10.1186/s12978-021-01070-6

3. Smiianov VA, Lyulyov OV, Pimonenko TV, Andrushchenko TA, Sova S, Grechkovskaya NV. The impact of the pandemic lockdown on air pollution, health and economic growth: system dynamics analysis. Wiadomosci lekarskie (Warsaw, Poland: 1960). (2020) 73:2332-8. doi: 10.36740/WLek202011102

4. Carr MJ, Steeg S, Webb RT, Kapur N, Chew-Graham CA, Abel KM, et al. Effects of the COVID-19 pandemic on primary care-recorded mental illness and self-harm episodes in the UK: a population-based cohort study. Lancet Public Health. (2021) 6:e124-35. doi: 10.1016/S2468-2667(20)30288-7

5. De Kock JH, Latham HA, Leslie SJ, Grindle M, Munoz SA, Ellis L, et al. A rapid review of the impact of COVID-19 on the mental health of healthcare workers: implications for supporting psychological well-being. BMC Public Health. (2021) 21:104. doi: 10.1186/s12889-020-10070-3

6. Zheng NS, Warner JL, Osterman TJ, Wells QS, Shu XO, Deppen SA, et al. A retrospective approach to evaluating potential adverse outcomes associated with delay of procedures for cardiovascular and cancerrelated diagnoses in the context of COVID-19. J Biomed Inform. (2021) 113:103657. doi: 10.1016/j.jbi.2020.103657

7. Waterfield KC, Shah GH, Etheredge GD, Ikhile O. Consequences of COVID-19 crisis for persons with HIV: the impact of social determinants of health. BMC Public Health. (2021) 21:299. doi: 10.1186/s12889-021-10296-9

8. Karako K, Song P, Chen Y, Tang W, Kokudo N. Overview of the characteristics of and responses to the three waves of COVID-19 in Japan during 2020-2021. Biosci Trends. (2021) 15:1-8. doi: 10.5582/bst.2021.01019

9. Rampal L, Liew BS. Malaysia's third COVID-19 wave - a paradigm shift required. Med J Malaysia. (2021) 76:1-4.

10. Mateen BA, Wilde H, Dennis JM, Duncan A, Thomas N, McGovern A, et al. Hospital bed capacity and usage across secondary healthcare providers in England during the first wave of the COVID-19 pandemic: a descriptive analysis. BMJ Open. (2021) 11:e042945. doi: 10.1136/bmjopen-2020-042945

11. Barasa EW, Ouma PO, Okiro EA. Assessing the hospital surge capacity of the Kenyan health system in the face of the COVID-19 pandemic. PLOS ONE. (2020) 15:e0236308. doi: 10.1371/journal.pone.0236308

12. Litton E, Bucci T, Chavan S, Ho YY, Holley A, Howard G, et al. Surge capacity of intensive care units in case of acute increase in demand caused by COVID-19 in Australia. Med J Aust. (2020) 212:463-7. doi: 10.5694/mja2. 50596

13. Noronha K, Guedes GR, Turra CM, Andrade MV, Botega L, Nogueira D, et al. The COVID-19 pandemic in Brazil: analysis of supply and demand of hospital and ICU beds and mechanical ventilators under different scenarios. Cad Saude Publica. (2020) 36:e00115320. doi: 10.1590/0102-311x00115320

14. World Health Organization (WHO). Weekly Epidemiological Update - 5 January 2021. WHO (2021).

15. Galbadage T, Peterson BM, Awada J, Buck AS, Ramirez DA, Wilson J, et al. Systematic review and meta-analysis of sex-specific COVID-19 clinical outcomes. Front Med (Lausanne). (2020) 7:348. doi: 10.3389/fmed.2020. 00348
Ciudad de México CM-SECTEI/200/2020 Red Colaborativa de Investigación Traslacional para el Envejecimiento Saludable de la Ciudad de México (RECITES).

\section{ACKNOWLEDGMENTS}

The authors appreciate the valuable comments that Dr. Mario Ulises Pérez Zepeda made on the manuscript.

16. Printz C. Poor COVID-19 outcomes and deaths linked to advanced age and pre-existing conditions. Cancer. (2021) 127:497. doi: 10.1002/cncr.33441

17. Carrillo-Vega MF, Salinas-Escudero G, Garcia-Pena C, GutierrezRobledo LM, Parra-Rodriguez L. Early estimation of the risk factors for hospitalization and mortality by COVID-19 in Mexico. PLoS ONE. (2020) 15:e238905. doi: 10.1371/journal.pone.0238905

18. Salinas-Escudero G, Carrillo-Vega MF, Granados-Garcia V, MartinezValverde S, Toledano-Toledano F, Garduno-Espinosa J. A survival analysis of COVID-19 in the Mexican population. BMC Public Health. (2020) 20:1616. doi: 10.1186/s12889-020-09934-5

19. Martos-Benitez FD, Soler-Morejon CD Garcia-Del Barco D. Chronic comorbidities and clinical outcomes in patients with and without COVID-19: a large population-based study using national administrative healthcare open data of Mexico. Intern Emerg Med. (2021) 1-11. doi: 10.1007/s11739-020-02597-5

20. Ortiz-Brizuela E, Villanueva-Reza M, González-Lara MF, Tamez-Torres KM, Román-Montes CM, Díaz-Mejía BA, et al. Clinical and epidemiological characteristics of patients diagnosed with covid-19 in a tertiary care center in Mexico City: a prospective cohort study. Rev Invest Clin. (2020) 72:165-77. doi: 10.24875/RIC.20000211

21. Stefan N, Birkenfeld AL Schulze MB. Global pandemics interconnected obesity, impaired metabolic health and COVID-19. Nat Rev Endocrinol. (2021) 17:135-49. doi: 10.1038/s41574-020-00462-1

22. Bello-Chavolla OY, Gonzalez-Diaz A, Antonio-Villa NE, Fermin-Martinez CA, Marquez-Salinas A, Vargas-Vazquez A, et al. Unequal impact of structural health determinants and comorbidity on COVID-19 severity and lethality in older Mexican adults: considerations beyond chronological aging. J Gerontol A Biol Sci Med Sci. (2020) 76:e52-9. doi: 10.1101/2020.05.12.20098699

23. Ortiz-Hernandez L, Perez-Sastre MA. Social inequalities in the progression of COVID-19 in the Mexican population. Rev Panam Salud Publica. (2020) 44:e106. doi: 10.26633/RPSP.2020.106

24. Jo MW, Go DS, Kim R, Lee SW, Ock M, Kim YE, et al. The Burden of disease due to COVID-19 in Korea using disability-adjusted life years. J Korean Med Sci. (2020) 35:1-10. doi: 10.3346/jkms.2020.35.e199

25. Nurchis MC, Pascucci D, Sapienza M, Villani L, D’Ambrosio F, Castrini F, et al. Impact of the Burden of COVID-19 in Italy: results of Disability-Adjusted Life Years (DALYs) and Productivity Loss. Int J Environ Res Public Health. (2020) 17:4233. doi: 10.3390/ijerph17124233

26. Oh IH, Ock M, Jang SY, Go DS, Kim YE, Jung YS, et al. Years of life lost attributable to COVID-19 in high-incidence countries. J Korean Med Sci. (2020) 35:e300. doi: 10.3346/jkms.2020.35.e300

27. Consejo Nacional de Población (CONAPO). Indicadores Demográficos de México de 1950 a 2050. (2020).

28. Instituto Nacional de Estadística y Geografía. Censo de Población y Vivienda 2020. (2020). Available online at: https://inegi.org.mx/app/tabulados/ interactivos/?pxq=Derechohabiencia_Derechohabiencia_01_3e83e8a1-690d4cfb-8af0-ale675979b3e (accessed February 15, 2021).

29. Organisation for Economic Co-operation and Development (OECD). OECD Data. Mexico: OECD (2020).

30. Secretaría de Salud. Bases de Datos COVID-19. (2020).

31. World Health Organization (WHO). Public Health Surveillance for COVID19. Interim Guidance. WHO (2020).

32. World Health Organization. International Guidelines for Certification Classification (Coding) of COVID-19 as Cause of Death. Based on 
ICD. International Statistical Classification of Diseases. World Health Organization (2020).

33. Secretaría de Salud. Lineamiento estandarizado para la vigilancia epidemiológica y por laboratorio de la enfermedad respiratoria viral. Secretaría de Salud (2021).

34. World Health Organization. Clinical Management of COVID-19. Interim guidance. World Health Organization (2020).

35. Unidad de Inteligencia en Salud Pública. Tablero analítico de seguimiento de casos documentados de SARS-CoV-2 en México. (2020). Available online at: https://www.insp.mx/informacion-institucional-covid-19.html (accessed February 15, 2021).

36. Murray CJ, Vos T, Lozano R, Naghavi M, Flaxman AD, Michaud C, et al. Disability-adjusted life years (DALYs) for 291 diseases and injuries in 21 regions, 1990-2010: a systematic analysis for the Global Burden of Disease Study 2010. Lancet. (2021) 380:2197-223. doi: 10.1016/S0140-6736(12)61689-4

37. National Institute for Health Care Excellence, The Scottish Intercollegiate Guidelines Network (SIGN) and The Royal College of General Practitioners (RCGP). COVID-19 Rapid Guideline: Managing the Long-Term Effects of COVID-19. Edinburgh: NICE (2021).

38. Greenhalgh T, Knight M, A'Court C, Buxton M, Husain L. Management of post-acute covid-19 in primary care. BMJ. (2020) 370:m3026. doi: 10.1136/bmj.m3026

39. Unidad de Transparencia Consejo Nacional de Población. Esperanza de Vida General, por Hombres y Mujeres, por Grupo Quinquenal a Partir de las Proyecciones de la Población de México y de las Entidades Federativas 20162050 de CONAPO. Solicitud de información 0416000010620. Aguascalientes: Consejo Nacional de Población (2020).

40. CONAPO. Población a Mitad de Año. Para la República Mexicana el Periodo es de 1950-2050, Para las Entidades Federativas de 1970-2 050. (2018).

41. Instituto Nacional de Estadística y Geografía (INEGI). Características de las Defunciones Registradas en México Durante Enero a Agosto de 2020. México: INEGI. (2021).

42. Pifarre IAH, Acosta E, Lopez-Casasnovas G, Lo A, Nicodemo C, Riffe T, et al. Years of life lost to COVID-19 in 81 countries. Sci Rep. (2021) 11:3504. doi: 10.1038/s41598-021-87 $640-x$
43. Charu V, Chowell G, Palacio-Mejia LS, Echevarría-Zuno S, Borja-Aburto VH, Simonsen L, et al. Mortality burden of the A/H1N1 pandemic in Mexico: a comparison of deaths and years of life lost to seasonal influenza. Clin Infect Dis. (2011) 53:985-93. doi: 10.1093/cid/cir644

44. Lee YR, Moon K, Kim YA, Park SY, Oh CM, Lee KS, et al. Disabilityadjusted life years for communicable disease in the Korean Burden of Disease Study 2012. J Korean Med Sci. (2016) 31(Suppl. 2):S17883. doi: 10.3346/jkms.2016.31.S2.S178

45. Yoon J, Oh IH, Seo H, Kim EJ, Gong YH, Ock M, et al. Disability-adjusted life years for 313 diseases and injuries: the 2012 Korean Burden of Disease Study. J Korean Med Sci. (2016) 31:S146-57. doi: 10.3346/jkms.2016.31.S2.S146

46. Grupo Técnico Asesor de Vacunación Covid-19. Sequential Prioritization for Vaccination Against SARS-CoV-2 in the Mexican Population. Preliminary Recommendations. Salud Publica Mex (2021) 63:286-307.

47. United Nations (UN). Human Rights: We Are All in This Together. UN (2020).

48. Tomson G, Causevic S, Ottersen OP, Swartling Peterson S, Rashid S, Wanyenze RK, et al. Solidarity and universal preparedness for health after covid-19. BMJ. (2021) 372:n59. doi: 10.1136/bmj.n59

Conflict of Interest: The authors declare that the research was conducted in the absence of any commercial or financial relationships that could be construed as a potential conflict of interest.

Publisher's Note: All claims expressed in this article are solely those of the authors and do not necessarily represent those of their affiliated organizations, or those of the publisher, the editors and the reviewers. Any product that may be evaluated in this article, or claim that may be made by its manufacturer, is not guaranteed or endorsed by the publisher.

Copyright (C) 2021 Salinas-Escudero, Toledano-Toledano, García-Peña, ParraRodríguez, Granados-García and Carrillo-Vega. This is an open-access article distributed under the terms of the Creative Commons Attribution License (CC BY). The use, distribution or reproduction in other forums is permitted, provided the original author(s) and the copyright owner(s) are credited and that the original publication in this journal is cited, in accordance with accepted academic practice. No use, distribution or reproduction is permitted which does not comply with these terms. 